\title{
La museología: una luz para ver nuestros museos
}

José Óscar Batres Posada

Los aspectos sobre museología que se abordarán a continuación son tan solo líneas preliminares que describen algunas de las experiencias de esta ciencia en nuestro medio. Es un amplio tema, del que ya se habla con propiedad. Museología es un término del que hasta hace algunos años poco o nada se comentaba, era casi desconocido y discutido con temor; pero hoy es parte del lenguaje comúnmente utilizado en los museos del país, lo que hace ver que, como ciencia, la museología esta penetrando en esta nueva atmósfera de los museos en El Salvador, posibilitando perfilar nuevas formas de cómo ver los museos en el futuro, que debería ser bajo la óptica científica.

La museología es recocida por el Consejo Internacional de Museos como la "ciencia de los museos". En sí es muy compleja, por la diversidad de aspectos teóricos y prácticos que se derraman de esta especialidad; su fin es planificar y ejecutar adecuadamente el trabajo técnico y científico que se realiza dentro de los museos.

Previo al abordaje de este importante tema, que sin duda es parte del andamiaje principal del desarrollo de todas las actividades de orden científico que se realiza en los museos, se planteará un panorama de cómo se ha introducido el término museología en nuestro país.

La museología en la actualidad comienza a ser un concepto del lenguaje cotidiano en nuestros museos, se pronuncia en muchas esferas académicas, pues a través de esta se derivan planteamientos científicos o discursos relacionados con nuestra cultura, por eso debe estar puesta en manos de especialistas, curadores, investigadores, conservadores, historiadores, antropólogos, arqueólogos, museógrafos y particularmente los museólogos. 
Sin embargo, algunos todavía se preguntan: ¿Qué es la museología? Dicho en pocas palabras, la museología es la parte abstracta de los museos, lo intangible, lo conceptual traducido a normas, recomendaciones, procedimientos y especificaciones; es lo filosófico de los museos; es, en sí, la teoría.

La aplicación museológica sin duda es puesta en práctica en todos los museos del mundo; refleja mucho énfasis en su labor científica, enfoca su importancia principalmente en el planteamiento y ordenamiento del contenido temático mostrado en las salas de exhibición; se preocupa de la veracidad, comprensión y claridad temática, donde a veces ingratamente no se observa en lo material el trabajo minucioso previo a la organización de una exposición de objetos.

El funcionamiento de los museos en la práctica descansa en buena parte en su labor científica dirigida por medio de la museología, a través de ella se refleja el resultado de las investigaciones que se desarrollan constantemente en los museos, ya que en la actualidad estos realizan un trabajo planificado y serio, enfocado particularmente a las colecciones que administran y resguardan en sus depósitos, labor que va acompañada de un permanente proceso de estudio, documentación, conservación y restauración de las colecciones.

\section{Una definición de la museología}

"Una ciencia aplicada, la ciencia del museo. Estudia la historia y la función en la sociedad, las formas especificas de investigación y conservación física, de presentación, animación y difusión, organización y funcionamiento, la arquitectura nueva o rehabilitada, los emplazamientos admitidos o seleccionados, la tipología, la deontología."1

La consolidación de la museología como ciencia y definición ha propiciado en los últimos cinco o seis decenios un largo debate, todavía no cerrado, no exento de posiciones encontradas y, sobre todo, de una confusión evidente al tratar los conceptos de museología y museografía.

1 Al respecto, George Henri Rivière, 1981). Georges Henri Rivière, fue el primer director del Icom (1946-1965). Es a quién se le adjudica la definición de museo que actualmente propone el Consejo Internacional de Museos; también contribuye enormemente a la crítica del museo tradicional y el nacimiento de la nueva museología mundial. De 1971 a 1982 organizó e impartió el Curso de Museología en la Universidad de París, donde transmitió sus ideas contestatarias a la museología dominante en esa época. 


\section{¿Como debe entenderse la museología?}

De acuerdo con Francisca Hernández Hernández, haciendo referencia a planteamientos teóricos, "la Museología es la ciencia del Museo. Ella tiene que ver con el estudio de la historia, trayectoria de los museos, su papel en la sociedad, los sistemas específicos de investigación, educación y organización, relacionado con el medio ambiente físico y las clasificaciones de los distintos tipos de museos". ${ }^{2}$ Ella parte de que "tradicionalmente, los aspectos teóricos de la museología han tenido un menor desarrollo que los prácticos, hasta el punto de que en los siglos XIX y XX todavía se seguía confundiendo la museología con la museografía. Es más, la dimensión teórica se centraba, sobre todo, en el conocimiento de la historia de los museos a través del estudio de la formación de las colecciones, su organización interna y los criterios expositivos. Sin embargo, esta teoría no estaba fundamentada en unos principios museológicos que tuviesen un valor objetivo universal. Esta situación ha llevado a que, a partir de los años cincuenta del siglo XX, algunos museólogos se propusieran elaborar una teoría museológica que tratase de clarificar qué debía entenderse por tal". ${ }^{3}$

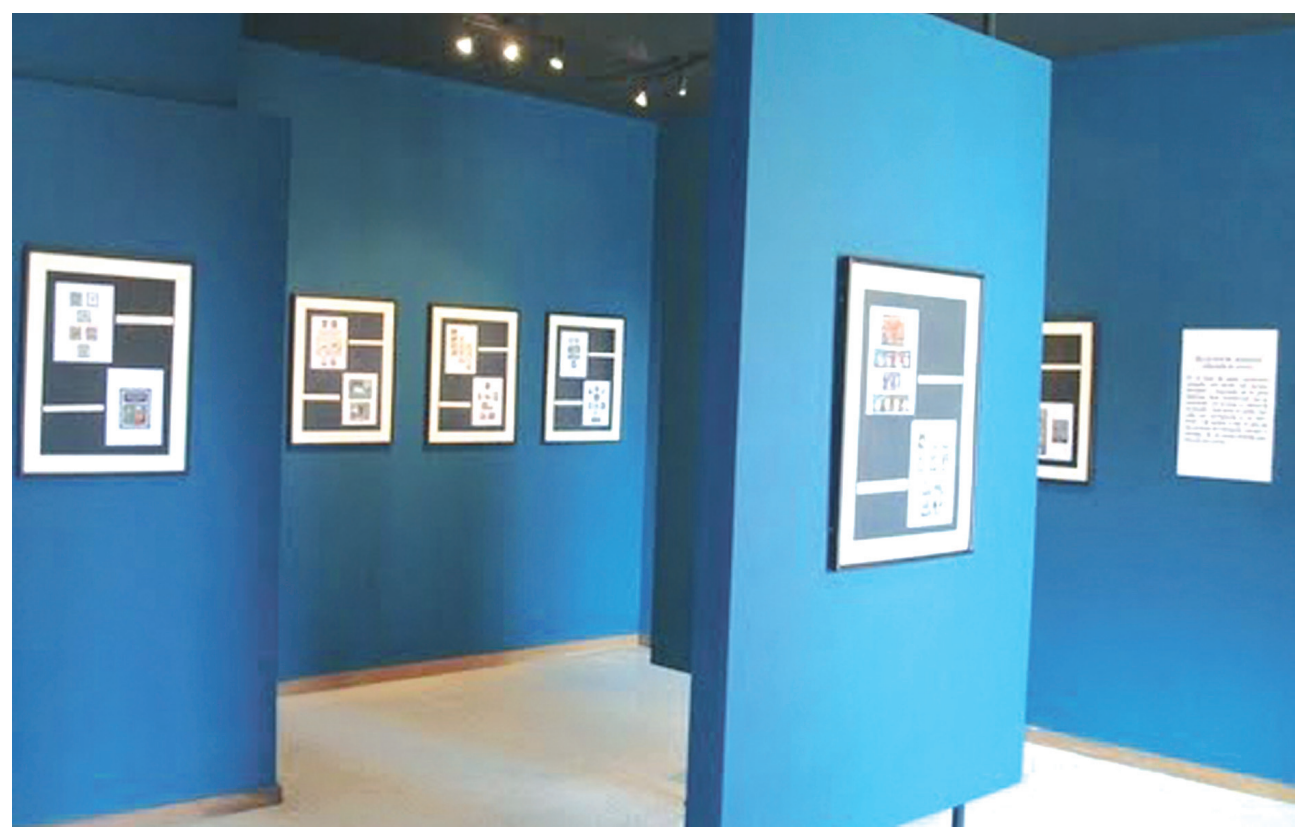

Exposición de sellos postales en el Muna

2 http://www.ujmv.edu/movil/asp/archivoContenido.asp

3 Hernández Hernández, Francisca, Planteamientos teóricos de la museología. Edit. Trea, S.L. Barcelona, España, 2006. P. 133. 


\section{Las colecciones, parte de la razón de ser de los museos}

El funcionamiento de los museos descansa en buena parte en el trabajo científico. La museología, en este caso, se involucra para dirigir sus interés hacia el resultado que se puede obtener mediante la investigación, estudio, conservación y difusión de las colecciones.

Sin restar mérito al trabajo administrativo y de coordinación que se ejecuta en los museos, prevalece el trabajo científico ya que proyecta a la institución museal a niveles académicos importantes, las colecciones que posee y exhibe se convierten en un referente para los investigadores si se toma en consideración el papel que asume el museo no solo como un espacio para exhibición, sino también como un centro de investigación y documentación que posibilita adentrarse mucho más al conocimiento de una especialidad de interés arqueológico, antropológico, histórico, artístico o de otra índole, según el carácter del museo.

Desde este panorama, se puede comentar de forma general sobre la importante labor de investigación realizada por nacionales y extranjeros en temas vinculados con la cultura nacional y otros temas afines, información que ha sido reconocida y utilizada en nuestro medio desde finales del siglo XIX, sin embargo, mérito y reconocimiento especial que debe asignarse a todos y todas los(as) investigadores(as) que han dedicado buena parte de su vida para ubicar fuentes informativas, formular hipótesis, aseverar teorías o plantear aproximaciones de aquellos temas asociados con nuestra realidad cultural al publicar sus trabajos de investigación.

\section{Experiencias acumuladas: reflexionando sobre la investigación realizada en los museos}

El Museo Nacional de El Salvador, desde su fundación el 9 de octubre de 1883, después de sus126 años de su apertura, se puede decir que fue la cuna donde dio inicio la investigación científica en los museos de nuestro medio, y también que, inicialmente, sus espacios reflejaban el concepto tradicional y dominante de museo interdisciplinario muy característico de aquella época y que posteriormente cambio su concepto; dedicó parte de su tiempo a la investigación arqueológica, paleontológica, etnográfica y de otras disciplinas, esfuerzos en los que también se involucraron muchos investigadores. 
Aquellas investigaciones acumuladas en el Museo Nacional se han reflejado a través de diversas publicaciones, tales escritos en la actualidad han servido como fuentes de referencia, en esta tan golpeada y difícil labor de la investigación. Conocida esa pequeña parte de sus antecedentes y

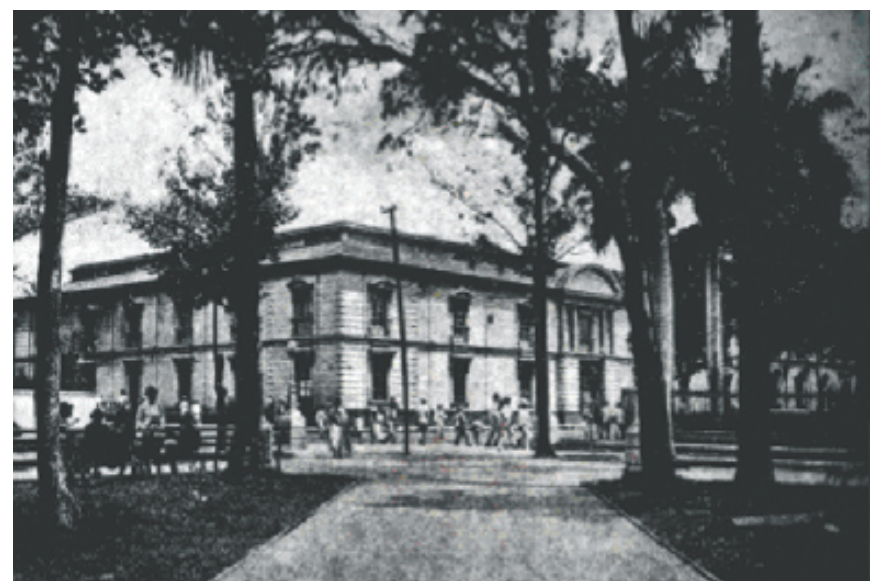

Edificio de la antigua Universidad de El Salvador, una de las primeras sedes del Museo Nacional su relación con el tema museológico, es posible equiparar el trabajo de investigación dentro del museo realizado en los últimos 39 años, período que está muy ligado al desarrollo museológico en la región mesoamericana, fuertemente apoyada e impulsada por México a través de las diferentes capacitaciones dirigidas al personal de los museos en la región.

Si bien se realizaba un trabajo de investigación en aquellos primeros años, luego de fundado el Museo Nacional, hay que decir también que para entonces dicha labor no reflejaba su presencia con amplitud en las salas de exhibición de los museos. Sin duda, siempre ha tenido mayor relevancia o prioridad la publicación de la investigación en contraposición a la información que podía ser expuesta en una sala de exhibición y complementada con una variada muestra de objetos.

El trabajo de investigación realizado dentro del Museo Nacional ha sido muy conocido en nuestro medio desde aquellos momentos; publicaciones como Tzumpame, Anales, la colección "Antropología e Historia” y otras, siguen siendo un principal referente de muchos investigadores, pero también se observa la necesidad de actualizar y generar nuevas investigaciones, que puedan complementar los referentes informativos existentes con investigaciones más recientes.

Sin embargo, no se debe perder de vista que las primeras y las subsiguientes investigaciones realizadas en el Museo Nacional casi siempre perfilaban un claro enfoque con interés de recuperar, describir, referenciar, asociar y de 


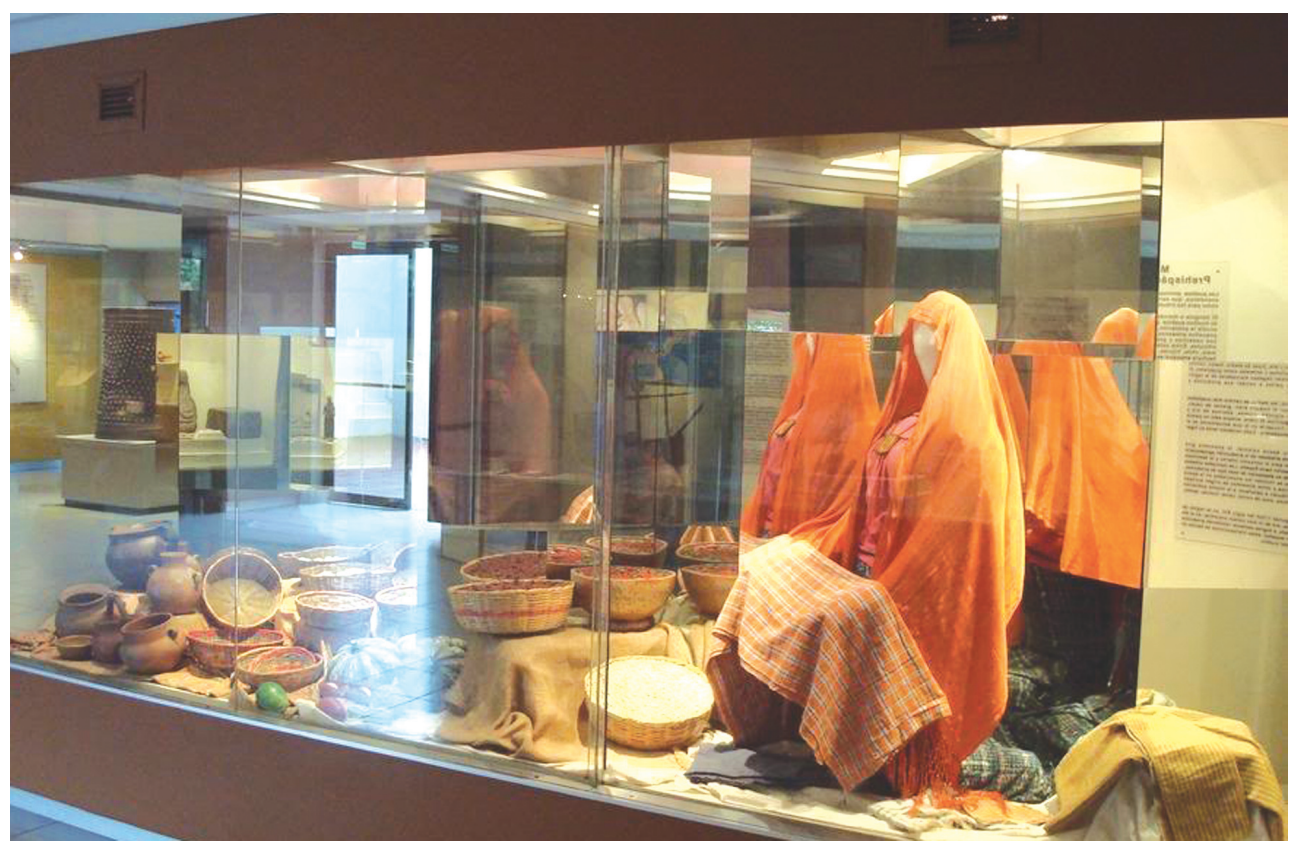

Sala permanente, Museo Nacional de Antropología "Dr. David J. Guzmán”

relacionar datos de interés científico - algunos posiblemente todavía en discusión - . Sin embargo, no es propósito de estas líneas cuestionar o confirmar tales posiciones, sino ver la información recopilada como insumo de primera mano para reconstruir el discurso temático de nuestros museos, en su mayoría con un dominio prevalente en lo antropológico y arqueológico; muy poco o nada se desarrolla lo puramente histórico para documentar aspectos importantes de nuestra cultura.

Es de reconocer que el trabajo de investigación no se ha detenido, sin embargo, se debe decir que para nadie es desconocido que parte de sus obstáculos han sido la nula o poca existencia de fuentes bibliográficas primarias en nuestro medio, lo que da doble mérito a los investigadores e investigadoras que buscan y localizan datos informativos fuera de nuestras fronteras, consultando bibliotecas, archivos, visitando museos y otras fuentes e instancias que complementen la recopilación documental de su investigación.

Es necesario referir que muchas de las investigaciones que se han realizado hasta el momento no fueron formuladas específicamente para estructurar guiones temáticos de los museos. Esto, en parte, se ha venido aprendiendo sobre la marcha, sin negar que hay algunos conocedores de estos procedimien- 
tos que se deben de poner en práctica dentro de los museos, y hay que brindar un crédito a la información formulada, pues ha sido la base de referencia para establecer parte de los contenidos de algunos museos; labor específica que corresponde a los museólogos o documentadores en los museos.

Se requiere hacer un alto para reflexionar sobre este tema, pues a pesar de que algunas de las investigaciones, aún cuando se hayan realizado dentro de los museos no fueron concebidas para fines divulgativos en las salas de exhibición. Esto puede dibujarse como un fenómeno que sirve para dejar al descubierto la falta de investigación específicamente formulada para las exposiciones, es sin duda una de las mayores debilidades de algunos museos, ya que su labor de difusión es limitada por muchos factores, entre ellos la poca presencia de investigadores que se dediquen específicamente a la labor de gabinete para trabajar en la actualización informativa de las salas de exhibición de los museos y desarrollar un fuerte trabajo en la documentación de las colecciones.

Los depósitos del acervo patrimonial gritan en silencio la necesidad de que sus colecciones sean documentadas para reconstruir su pasado y formular nueva información que contribuya al contenido de los museos, para publicarse y propiciar mayor conocimiento sobre diversos temas de nuestra cultura.

No es propósito de este artículo poner en tela de juicio la investigación realizada, si no ser objetivos en señalar los vacíos que existen en nuestros museos. Tampoco es el fin comentar la cronología de las investigaciones, ya que sería injusto dejar de mencionar algunos nombres de los que dedicaron su vida a esta ardua labor; sin embargo, se debe decir que este es un tema especial que hoy no se puede desligar de la museología. Por consiguiente, es necesario tomarla de referencia como una parte del trabajo museológico que se ha comenzado a construir, que sirva para reflexionar en lo que se ha hecho y en lo que se debe de hacer a través de la investigación en los museos: actualizar sus discursos y mejorar su contenido.

Mucho se ha comentado sobre el papel de los museos en términos de facilitar el conocimiento, de ser complemento de la educación formal, de ser un medio de educación no formal. Se cuestiona: ¿qué tanto complementa a la educación? ¿En qué medida se asocian los contenidos del museo con los programas formales de educación? Estos, entre otros aspectos, nos deben poner atentos 


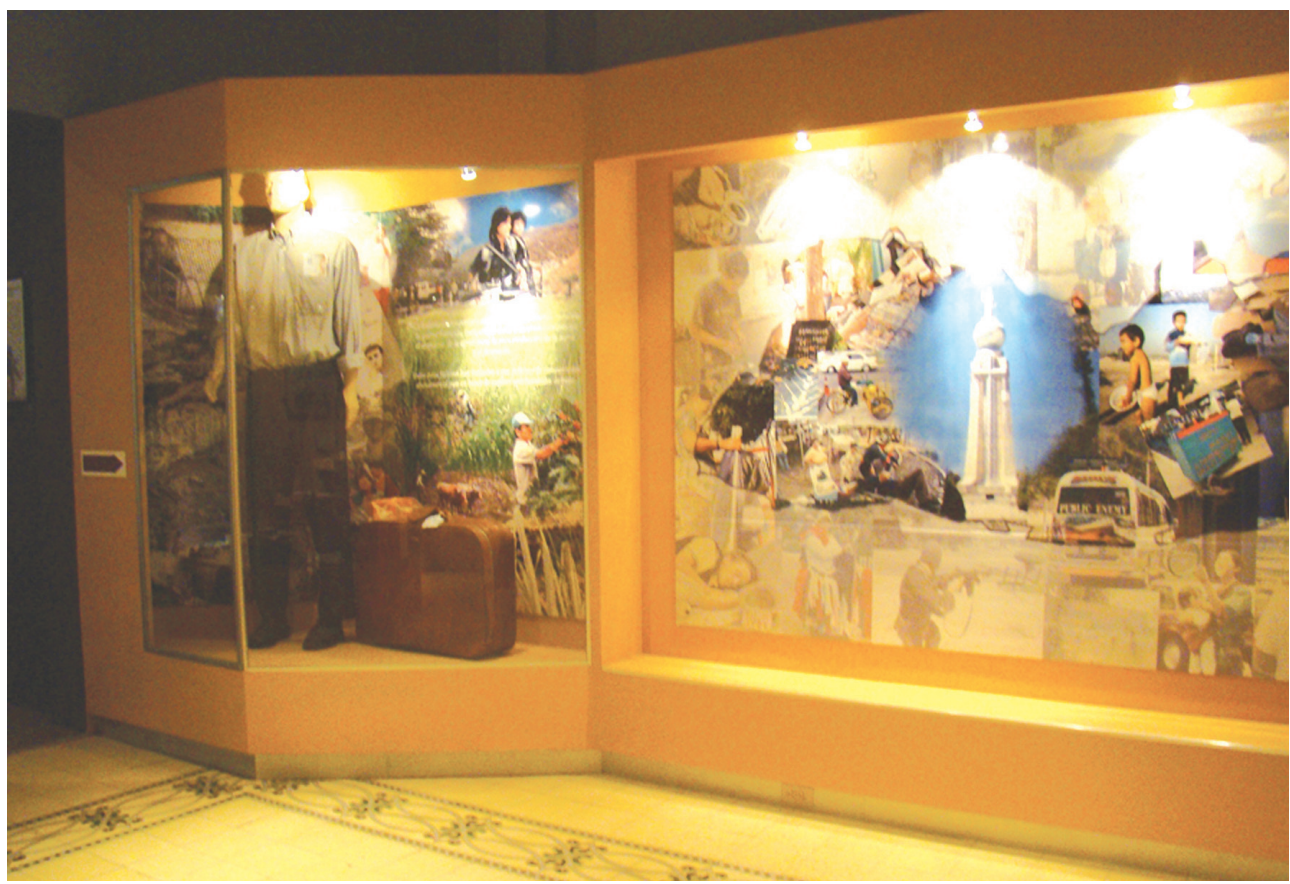

Sala "Las migraciones", Museo Universitario de Antropología, Utec

sobre la responsabilidad que existe de conocer y resguardar nuestro legado histórico. Sobre esto se debe reflexionar que los museos no son solo para los estudiantes pero si son para un público cautivo importante, también los museos deben abrir sus espacios a una diversidad de públicos más amplia, que va desde el estudiante; las amas de casa, el turista, el especialista, el obrero y otros, que busquen y encuentren información asociada a su cultura, con su realidad, que se sienta identificado.

El trabajo académico es importante para el desarrollo intelectual; pero debemos bajar al grueso de la población. La museología es un medio interlocutor que posibilita el diálogo en los museos. Por consiguiente, se debe pensar en un discurso comprensible además de educativo, más reflexivo. Por tanto, es necesario impulsar y elevar la importancia de la museología en los museos a partir de la investigación, ya que esta puede contribuir a facilitar que el público acceda al conocimiento, identificar, valorar, fomentar su sentido de pertenencía y de arraigo con su identidad. Es imprescindible ver a la museología como el medio para tejer el conocimiento a través de los hilos de la ciencia y nos posibilite acercarnos a nuestra realidad histórica. 
De la experiencia observada en el trabajo de investigación y exhibición museográfica en los museos nacionales durante los últimos 33 años, se debe destacar que sí se ha hecho investigación; pero que solo un mínimo porcentaje de estos resultados han sido reflejados directamente en las salas de exhibición, $\mathrm{y}$, sin detrimento de esta importante labor en los museos, se debe exaltar la producción de publicaciones de aquel importante momento de la Administración del Patrimonio Cultural, institución que condujo el trabajo de nuestra cultura en la década de los setenta, donde participaron muchos investigadores e investigadoras que dejaron su legado bibliográfico, que hoy sirve como referencia para los que inician sus pasos en la investigación antropológica, arqueológica e histórica.

\section{La lectura museológica}

La lectura y contenido temático de los museos es un aspecto que se puede percibir en el discurso expositivo planteado en las salas de exhibición, aún cuando se pueda mantener el concepto tradicional de museo, en algunos museos atribuido en parte a la poca experiencia y desarrollo de conceptos diferentes al del museo actual. Dicho en otras palabras, es un síntoma que merece un estudio especial, pues hace falta profesionalizar, en nuestro medio, el trabajo museológico, llevarlo a otras instancias y elevarlo a niveles de mayor importancia académica; es una necesidad que desde hace mucho tiempo se ha hecho sentir en nuestros museos.

El inicio de los cambios de contenido en los museos nacionales durante la década de los setenta coincide con el impulso y presencia de la ciencia museológica, que se asentó en nuestro medio al ver al Museo Nacional como generador de investigaciones. Si no, veamos lo que pasa hoy.

En aquel momento la división del trabajo en el museo estaba definida, las salas de exhibición se hacían sentir como un espacio aislado destinado para exponer algunas colecciones con cierto orden y sin sentido interpretativo; no por la falta de investigadores, sino más bien porque no se construía información para los museos. La situación de aquella época no difiere mucho a la realidad que hoy afrontan algunos museos, quizás no todos, pero sí la mayoría de los museos nacionales, donde la formulación de guiones temáticos diseñados por documentadores es una necesidad permanente para exponer la información. 
Se debe tener en cuenta que en aquella etapa donde la producción bibliográfica fue manifiesta, esta respondió a un esquema de hacer trabajo de campo muy importante por sus resultados - invaluables, si se quiere - , y que contribuyó a documentar el patrimonio cultural tangible e intangible hasta donde fue posible, hecho sin duda trascendental, ya que no se ha vuelto tener otras experiencias similares que documenten de esa manera nuestro patrimonio cultural.

Hoy en particular se adolece de la falta de información en algunas áreas de la investigación antropológica, arqueológica e histórica por el hecho de no mantener una continuidad en las investigaciones. No hay duda de que se esta investigando, y se sabe que toma tiempo afinar los detalles informativos para publicar con veracidad; sin embargo, hace falta en nuestro país un programa formal enfocado a documentar los aspectos relevantes de nuestra historia, que en buena parte se vean reflejados en la documentación de las colecciones que reguardan los museos nacionales, las que se estudian muy limitadamente.

La museología, de forma incipiente — sí se quiere decir de algún modo-, comenzó a tener presencia en nuestro medio en la década de los setenta, fue cuando la Administración del Patrimonio Cultural se distinguió por ser muy prolija en la investigación y producción bibliográfica, curiosamente también coincidió que en otros países la museología comenzaba a tener un protagonismo muy importante; México, por citar un ejemplo, con el impulso de la investigación antropológica, arqueológica e histórica reflejada en sus museos dio un salto significativo como respuesta museológica.

\section{Un asomo a nuestra realidad museológica}

A principios de los años setenta se hacía sentir en el Museo Nacional la dependencia informativa y las escasas fuentes bibliográficas, donde la limitada producción de publicaciones de carácter antropológico, arqueológico e histórico a escala nacional fueron posteriormente temas de dominio en las principales investigaciones de aquel especial momento dentro de la Dirección de Patrimonio Cultural; se comenzó a generar nueva información, muy valiosa para actualizar el contenido de las exhibiciones. Como experiencia de este momento, se tuvo como resultado el replanteamiento temático del Museo Nacional "Dr. David J. Guzmán”, enfocando su contenido a los tópicos antes mencionados, un claro ejemplo del trabajo científico que coincidió con el nuevo enfoque museológico al que deberían responder los museos. 
Un aspecto curioso que vale la pena mencionar, en el proceso de investigación, es que lo iniciado en los años setenta tuvo como resultado algo inusitado, pues, a partir de mediados de la década de los noventa hasta el año 2002, se planteó un cambio sustancial en el concepto de contenido del Museo Nacional, definiendo su nueva lectura y presentación museográfica con la conjunción de un grupo de profesionales que contribuyeron en la formulación de un nuevo concepto temático dentro del museo, donde antropólogos, arqueólogos, historiadores, etnólogos, arquitectos y museógrafos participaron en el proceso investigación, diseño y montaje del nuevo Museo Nacional de Antropología “Dr. David J. Guzmán”. Esto es lo que se debe destacar en el trabajo realizado, la presencia de los investigadores dentro de los museos para estructurar y proyectar el trabajo científico institucional.

De esto se puede decir que la presentación museográfica casi siempre adolece de las limitaciones y carencias informativas en los museos; el planteamiento temático de nuevas exhibiciones toma tiempo para su estructuración, por consiguiente, es necesario mantener el diálogo permanente entre los investigadores y museógrafos, dinámica que sirve para madurar y consolidar no solo el discurso temático, sino también el diseño y la presentación de las exhibiciones, pues el trabajo dentro de los museos es un trabajo en equipo.

\section{La acumulación de conocimientos no difundidos: investigaciones que engordan los archivos}

"Todo discurso puede ser entendido como una 'metamorfosis de efectos' que produce, a partir de sí misma, otra forma de discurso: la historia. La historia, en este caso, se refiere al conjunto de hechos ocurridos en el espacio y en el tiempo que a 'la nueva realidad', reinstaurada por aquellos que narran los hechos." - Jean-François Lyotard

El fin de los museos es mostrar o exhibir el resultado de las investigaciones, difundir el trabajo científico a través de las publicaciones, organizar exposiciones temporales o itinerantes, facilitar el conocimiento a través de las salas permanentes de exhibición del museo, ciclos de conferencias y otros.

Es muy probable que muchos escritos e investigaciones de importancia han quedado en el tintero por distintas razones - como se dice, "engordando los 
archivos" - sin que sean publicados. Toda labor de investigación en buena medida debe ser divulgada, no es positivo el acumulamiento informativo sin que tenga un receptor final: el público deseoso de conocer.

No se debe ignorar o menospreciar el medio utilizado para divulgar e informar sobre el resultado de las investigaciones, sea este un libro, una conferencia, un guión televisivo o radial, una exposición, cualquiera que fuere, se debe pensar que existe un receptor. Sin embargo, una prioridad por atender es la información formulada para ser divulgada a través de los museos.

Sin duda, muchas de las investigaciones realizadas han servido de base para la estructuración de los guiones temáticos, algunas reflejadas en las salas de exhibición de los museos como producto del esfuerzo, tiempo y entrega personal que muchos investigadores destinaron a su trabajo profesional. En ese sentido, los nombres de muchos investigadores que se listan a continuación son un referente de una labor informativa y documental que existe en nuestro medio. No están todos, pero que sí se sabe del trabajo de los no mencionados, y este siempre será una luz para alumbrar el conocimiento de nuestra historia dentro de los museos. A ellos una disculpa; pero también su reconocimiento.

- David Joaquín Guzmán

- Tomas Fidias Jiménez

- Stanley Boggs

- Gloria de Gutiérrez

- Pedro Escalante Arce

- América Rodríguez

- Concepción Clará de Guevara

- Carmen Hugueth

- Efraín Cerna

- Pilar Lagos

- Carlos Lara

- Marlon Escamilla

- Paul Amaroly

- Fabricio Valdivieso

- Manuel López

- Ramón D. Rivas

- Knut Walter

- Rafael Cobos

- Gilberto Aguilar

- Daniel Aguilar
- Santiago I. Barberena

- Pedro Geofroy Rivas

- Payson Shetts

- Enrique Kuny

- Carlos Cañas Dinarte

- Maribel Henríquez

- Lorenzo Amaya

- María Eugenia López

- Rafael Vela

- Jaime Miranda

- Vicente Genovés

- Heriberto Erquicia

- Rafael Alas

- Shione Shibata

- Ana Lillian Ramírez

- Mario Romero

- Willian Fowler

- Roberto Gallardo

- Azalea de Granados 
En realidad hay otros investigadores nacionales y extranjeros que han realizado algún trabajo de investigación en nuestro país; a esta lista también debe agregarse el reconocimiento a los investigadores de otros museos estatales, de iniciativa privada, locales o comunitarios.

\section{Ordenar el contenido de los museos: definir el discurso temático a través de la investigación}

Hacer una revisión del contenido temático en los museos estatales sería una tarea muy difícil; pero es necesario hacer un diagnóstico sobre el contenido de los museos, cuyo enfoque sirva para llenar los vacíos informativos y conciliar con las fuentes bibliográficas de referencia, para actualizar e incorpo-

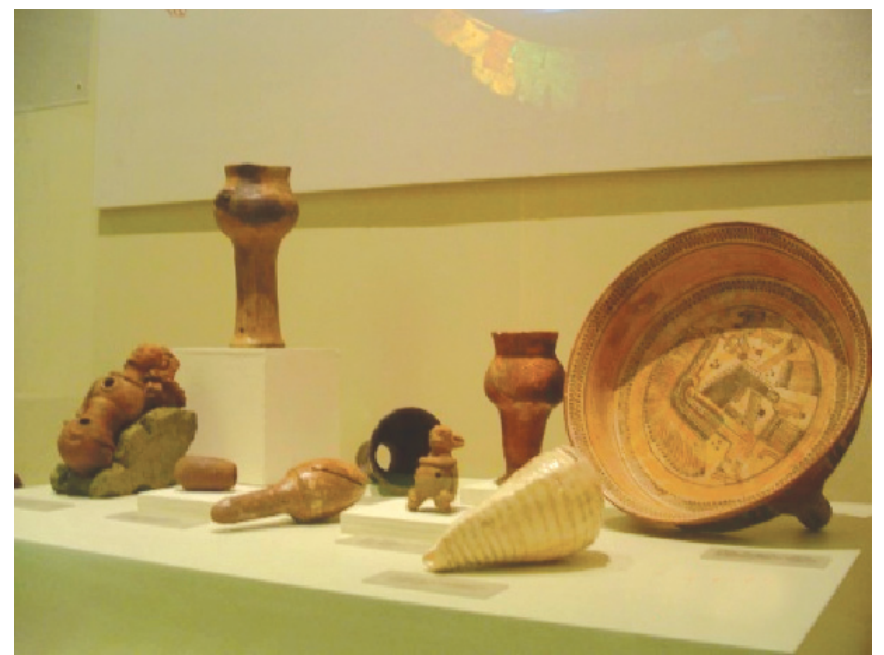

Colección de instrumentos musicales prehispánicos, Muna rar la nueva información planteada en las investigaciones más recientes.

Desde que se inició el trabajo de exhibir colecciones en los museos estatales, ya sea el Museo Nacional de Antropología, los museos de sitio, luego los museos regionales, y posteriormente otros como el caso del Museo de Historia Natural y en último caso el Museo de los Tres Poderes del Estado y el Museo de Historia de El Salvador dentro de estos se debería reflexionar en los procesos de documentación, pues siempre ha existido una preocupación sobre la información por exponer respaldada por los investigadores.

Con la reapertura del Museo Nacional de Antropología a principios de la presente década, también fue creada la Coordinación de Museos Nacionales, ente reconocido para administrar técnicamente los museos de los sitios arqueológicos Tazumal, Casa Blanca, Joya de Cerén y San Andrés, los museos regionales, el de Occidente ubicado en Santa Ana y el de Oriente ubicado en 
San Miguel; a estos se agregan los museos ubicados en San Salvador: el Museo de Historia Natural, el Museo de los Tres Poderes del Estado y el Museo de Historia de El Salvador en proceso de formación.

A través de la Coordinación de Museos Nacionales, instancia estatal a través de la cual se comenzó a desarrollar un trabajo de equipo museológico y museográfico, especialmente con el departamento de Arqueología, en particular con el Lic. Shione Shibata, quien realizó el diseño de los guiones temáticos y curaduría de las colecciones por exponer, para la actualización de los contenidos de los museos de los sitios arqueológicos Tazumal y Casa Blanca, entre el año 2007 y 2008, se realizaron estas dos de las más recientes experiencias que ilustran la importancia de la investigación realizada por profesionales competentes en su especialidad.

Cabe destacar la labor realizada por la Coordinación de Museos Nacionales juntamente con el departamento de Arqueología, ambas instancias pertenecientes a la actual Secretaría de Cultura, que con un trabajo de equipo se logró la ejecución del proyecto de diseño y montaje museográfico, que dejó como

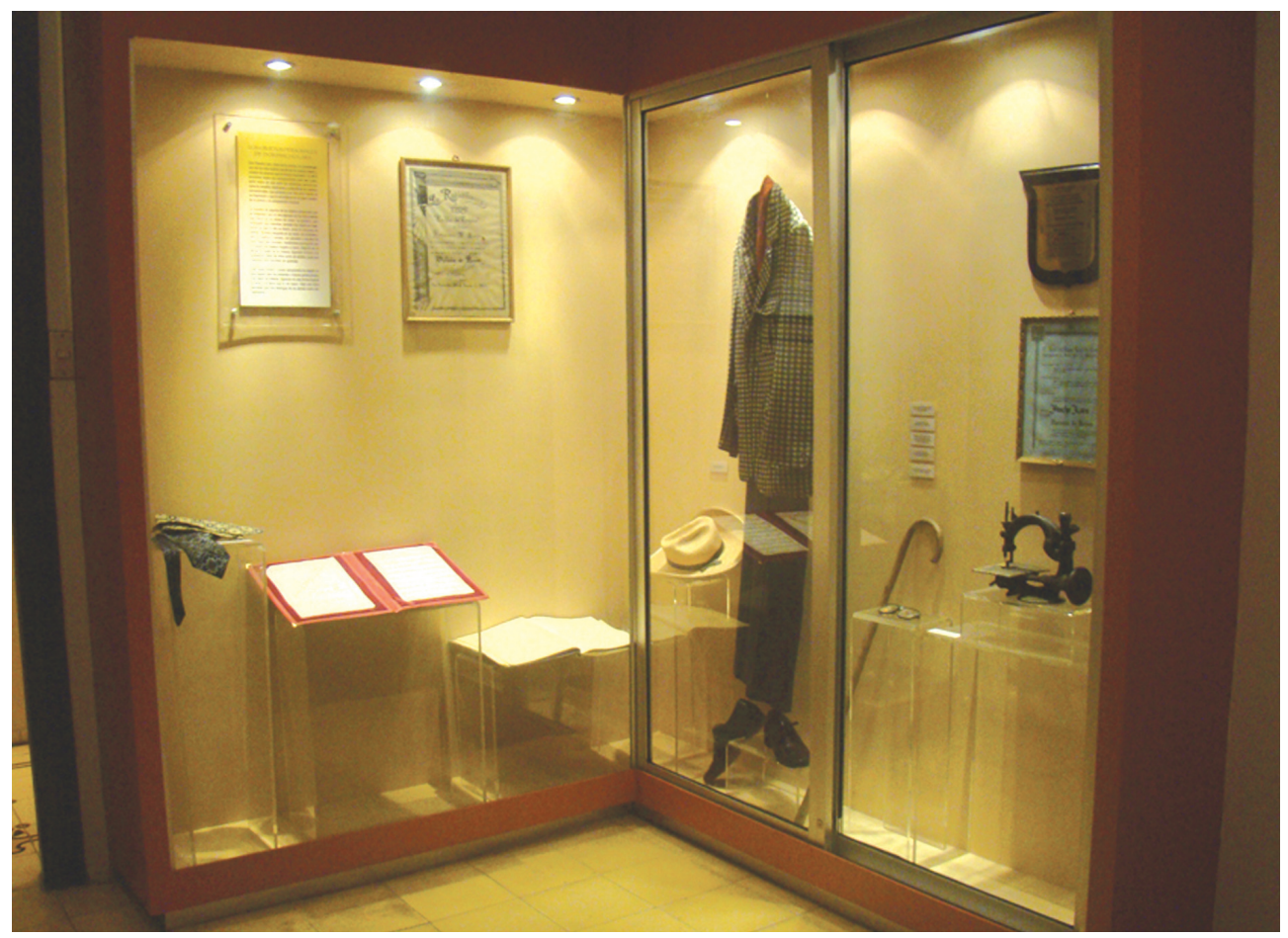

Sala "Pancho Lara", MUA 
resultado, entre los años 2007 y 2008, la instalación de dos museos de sitio con un planteamiento informativo actualizado sobre las investigaciones en la zona de Chalchuapa.

\section{No se debe manosear el trabajo museológico}

Los temas que se abordan en las salas de exhibición de los museos deben ser con base en el producto de las investigaciones formuladas por arqueólogos, antropólogos o historiadores y otros especialistas según sea el carácter del museo.

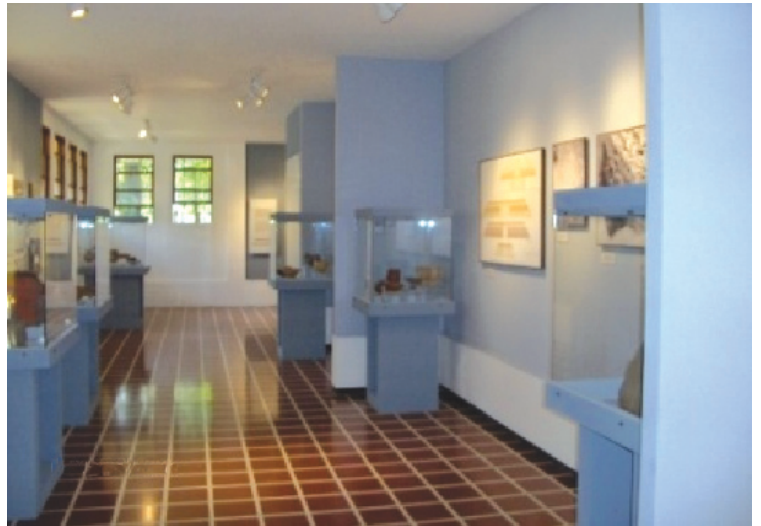

Salas de exhibición del museo arqueológico del sitio Tazumal

Sin embargo, en algunos discursos expositivos se cubre solo una parte de todo un universo informativo. Se nota que en algunos temas planteados el contenido de las exhibiciones se reflejan vacíos informativos, se plantean temas que no se asocian con la totalidad de la exhibición, se rompen eslabones que dejan a libre juicio del lector sacar conclusiones, cuando es el museo mismo el que debe clarificar los aspectos informativos.

Esto suele suceder en ciertos casos, sobre todo cuando no se respeta el planteamiento del investigador; cuando se interfiere en la secuencia del guión,

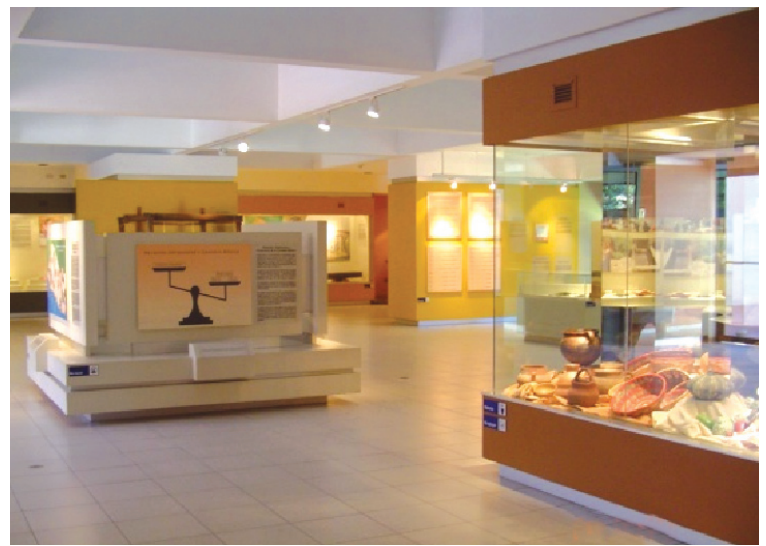

Sala de exhibición del Museo Nacional de Antropología, año 2003 ya sea por la imposición de criterios herrados o razones particulares impulsadas y dominadas por sentimientos personales, más que por criterio científico.

Se debe ser precisos y cumplir con el rigor de la evidencia documentada y comprobada con datos sugeridos por el investigador cuando esta información será mostrada en una 
exhibición, ya que se observa que, cuando existe una base informativa, se hace sentir la libertad de juicio documentada, con la que se puede inferir en el manejo de algunos datos para abrir nuevas perspectiva sobre una visión informativa.

No hay que perder de vista que se debe comenzar a dar apertura a nuevos planteamientos surgidos por la investigación, pues no es posible estar dependiendo de las mismas fuentes documentales, puesto que de algunas de estas se pone en duda su veracidad. Es bueno criticar, y el presente es un buen momento para reflexionar y dirigir el rumbo de las investigaciones y publicar.

Es necesario posicionar el país en el tinglado de las investigaciones con nuevos datos acerca de nuestra cultura. Si bien en algunas áreas de investigación se critica fuertemente, es necesario decir que también es saludable proponer soluciones sobre los errores, ya que la investigación es un tema de permanente discusión, y siempre será comentar sobre la veracidad de la información. Dirán unos "estas son primeras aproximaciones", y sin duda lo serán siempre; pero hay que publicarlas, difundirlas y compartirlas, considerar que hay una diversidad de lectores. Muchas de las investigaciones podrán leerlas a través de los museos.

\section{La lectura informativa en los museos: el guión como base del hilo conductor en las salas de exhibición}

Hay diversas maneras de cómo se ve reflejado el trabajo museológico. Una de las principales es la investigación dirigida a los temas que se difunden a través de las salas de exhibición; sea para exhibiciones permanentes, temporales o itinerantes, en cualquiera de los casos la investigación define los temas informativos por medio del guión museológico.

El guión temático o científico es el instrumento que se formula para definir y ordenar el contenido de la exhibición, propone los recursos museográficos de la exhibición, entre ellos la colección, la información, los recursos de apoyo informativo, inclusive sugiere fuentes bibliográficas de referencia.

La investigación formulada para una exhibición por lo general siempre sugiere el orden que se debe seguir para comprender su contenido. Esta se plantea a veces en una secuencia cronológica o temática, inclusive se puede hacer una combinación de ambas posibilidades, con el propósito de facilitar la com- 


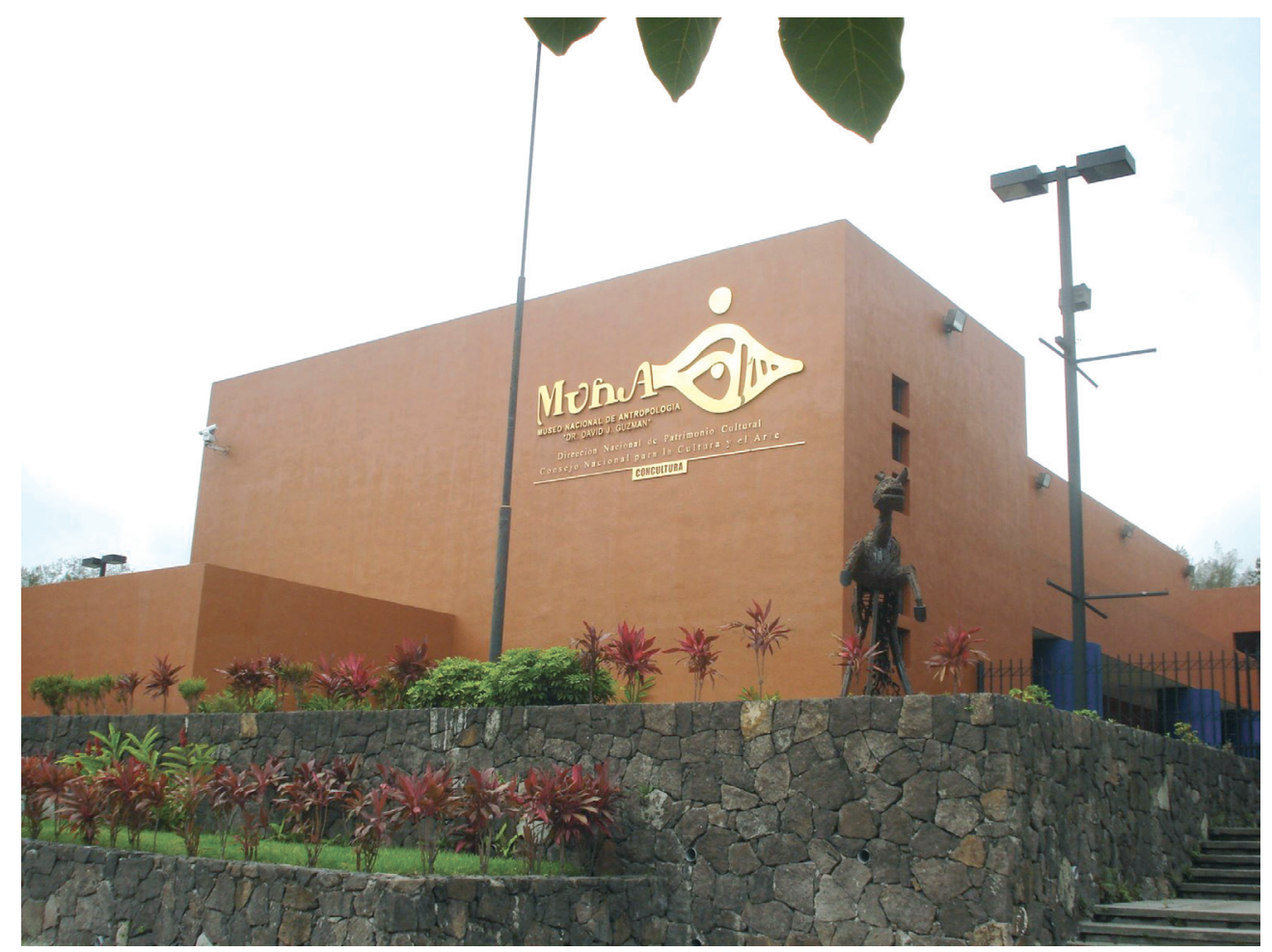

Museo Nacional de Antropología, “Dr. David J. Guzmán, Muna

prensión informativa de la exhibición. Otra parte del trabajo museológico es la curaduría de las colecciones, trabajo dirigido a documentar los objetos. Su propósito es describir su historial y asociarlo con hechos relevantes; es decir, que a través de los objetos se cuenta una historia, el investigador la interpreta y la propone como parte informativa en el discurso museográfico, destaca los datos de mayor relevancia, pues el curador debe conocer su historial y condiciones de movilización de los objetos.

\section{Aplicación museológica en nuestro medio: lo práctico se contrapone a lo científico}

La museología como tal comprende todo lo teórico de los museos, ordena el trabajo científico mediante normas, establece procedimientos de actuación profesional, enfatiza la investigación dentro de los museos, esto con el fin de que los bienes culturales mantengan el tratamiento adecuado en su manejo informativo, ya sea en áreas de exhibición, depósito, estudio o reservas de referencia. 
El desarrollo museológico en nuestro país tuvo sus inicios con la creación del Museo Nacional. Quiérase o no, sus experiencias comenzaron a crecer a partir del momento en que las colecciones se constituyeron como producto de las incipientes investigaciones, recolecciones de campo o posibles donaciones, estas tuvieron como primer recinto de trabajo de documentación un espacio adjunto a la antigua biblioteca de la Universidad Nacional. El museo comenzó allí su labor científica, museológica y museográfica.

Sin conocerse a plenitud la ciencia museología en aquella época, sin tener un manual de aplicación, sin que el personal tampoco haya podido tener una formación técnica y mucho menos un conocimiento académico universitario; a pesar de todo, aquellos años el Museo Nacional daba sus primeros pasos.

Es muy probable que haya fuentes bibliográficas que describan de alguna manera el trabajo científico de aquella de apoca; pero también - hay que decirlo - que sin ser reconocida como tal, ya se hacía museología de forma empírica. Fue sin duda un trabajo práctico, que dejó las primeras experiencias descritas en algunas publicaciones que hoy conforman el acervo bibliográfico de la nación. Todo se inició sin manejar una determinada teoría museológica, prevaleció claramente el criterio de los investigadores.

Hay que decir, también, que esa práctica solo el tiempo podrá juzgarla, si fue buena o fue mala; pero sí es evidente que dejó una base importante de experiencias, de las que ahora muchos se pueden considerar "eruditos" en el manejo de la información generada en aquel momento, pues se han alimentado de aquellas posibles equivocaciones que afloran en todo inicio, pero que ahora son parte de la sabiduría de muchos. Este comportamiento se observa especialmente en algunos investigadores que, en su afán científico, hacen ciencia a partir de los errores de otros.

Las ciencias, como principio razonado, siempre pretenden ser exactas; pocas dejan espacio a las consecuencias de lo deductivo o de lo supuesto, casi nunca permiten lo inductivo, menos ir de lo particular a lo general, no dejan fisuras para la imaginación o a la recreación hipotética que permita reconstruir sucesos o hechos importantes en el devenir de la vida del hombre y de su entorno. Los investigadores son así, y se respeta su posición.

Sin embargo, las investigaciones siempre tratan de ser probatorias, considerando un mínimo margen de error, y si bien permiten concluir hipótesis, a 
veces no se establecen con certeza las conclusiones de una teoría muy opuesta a lo práctico. Como ejemplo, en una exhibición por lo general se observan las pobres descripciones de los objetos mostrados, pues por falta de documentación y una mayor interpretación estos se describen de forma simple y, sobre todo, resaltando datos que para el público son obvios sin necesidad de una información adicional, que a veces es muy técnica; pero sí se deja de decir sobre su uso, significado, ornamentación, técnicas u otros datos, pues no se reconstruye su historia, se utiliza comúnmente un vocabulario que solo los hombres de ciencia o los especialistas conocen y que el público en general nunca asimila.

\section{Retos y proyecciones: las capacitaciones del personal, un área de estudio que requiere de elevar el nivel académico profesional de esta especialidad en nuestro medio}

El trabajo museológico en nuestro medio ha venido en ascenso en los últimos años. Mención especial merece, a manera de ejemplo, el Museo de Arte, Marte, con la movilización de exposiciones muy importantes, muestra obras en exposiciones de alta relevancia artística, tanto por la autoría de las obras, como por su procedencia y expresión plástica. Este trabajo requiere de un conocimiento, de una experiencia calificada, cumplir con el rigor de las normas que exige el trabajo de los museos; esto es, la aplicación de los preceptos museológicos.

Si bien ya no se ignora la necesidad de actuar profesionalmente en el campo museológico, el desarrollo académico de esta especialidad a escala regional, ha dado los primeros pasos. Otros países, como Costa Rica, han elevado su exigencia académica de la museología como carrera universitaria, lo que garantiza las capacidades y competencias profesionales en la región.

La administración y proyección de la cultura no es nada fácil, es parte de las preocupaciones museológicas, es un desafío, como lo es también la responsabilidad de investigar, rescatar, conservar y difundir el patrimonio cultural. Se deben hacer los esfuerzos para compartir esta responsabilidad, pues ingrato sería ver solo a una instancia tratando de asumir tal responsabilidad. En ese caso, a la institución oficialmente reconocida con la responsabilidad de investigar, conservar y difundir el patrimonio cultural. Creo que no debe ser así. La apertura es importante, y se debe pensar en garantizar el futuro de los 
museos con la presencia de profesionales que desarrollen el trabajo científico en beneficio de la colectividad.

\section{Cultura de museos, un desafío o una realidad por afrontar}

- Cada país tiene su propia experiencia respecto al aprovechamiento del papel de los museos. No se puede comparar, tampoco es saludable adoptar patrones que no se adapten a la realidad social, educativa, económica y cultural de un determinado país.

- Es innegable que los museos, como recurso de educación y espacio culturizador, podrán ser un recurso que puede brindar a cada conglomerado una posibilidad de mostrar y recuperar su identidad, de reflexionar, de educarse; sin embargo, debe de contarse con una política estatal de educación que refuerce sustancialmente este componente para generar, en lo sucesivo, un cambio de pensamiento dirigido a la valoración y apropiación de la cultura nacional.

Esta es una realidad de la que adolece nuestro país, y que, por consiguiente, repercute en nuestra identidad.

\section{La necesidad de musealizar el patrimonio cultural}

- Es innegable la necesidad de asignar y reconocer la importancia y valorización de los bienes culturales. Los museos, en parte, cumplen esta función, sin dejar de considerar que el patrimonio cultural debe servir para el desarrollo de los pueblos.

- No se debe ignorar que todos los bienes de importancia histórica, artística y ambiental constituyen la herencia cultural patrimonial de una sociedad, y que esta tiene la responsabilidad de ponerla a su alcance para el goce y disfrute, sin distingos de clase, posición social y económica, ideología, raza, creencia religiosa y otros. Los museos deben ser un espacio concebido para el conocimiento, la reflexión y, sobre todo, para permitir la constante apropiación y búsqueda de la identidad. 


\section{Comentario final}

En nuestro medio se han comenzado a dar los primeros pasos en la profesionalización de algunas áreas asociadas con la museología. El abrir las carreras universitarias de Antropología y Arqueología, en la Universidad Tecnológica de El Salvador, manifiesta una intención de compromiso, al igual que la Universidad Nacional; esto es también asumir una responsabilidad con nuestra sociedad y con nuestra cultura, ya que así se esta contri-

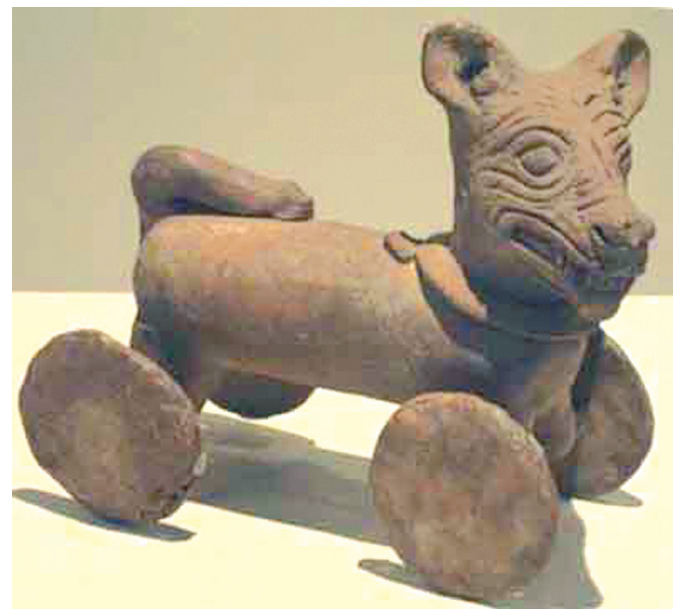

"Perrito con ruedas" procedente del sitio arqueológico Cihuatán. Sala "Asentamientos humanos", Muna buyendo en la preparación de profesionales nacionales en áreas científicas importantes, lo que garantiza a futuro el desarrollo de nuevos proyectos. Así mismo, es necesario retomar o comenzar a generar nuevas investigaciones que abran las perspectivas en el intercambio científico con otras universidades, haciendo posible no depender de otras instancias, posicionando la investigación en el ámbito científico, ya que esta no debe estar relegada, más bien debe ser protagonista en el amarre de los eslabones de la historia, para que contribuya a fortalecer las bases de nuestra identidad. Ver y construir desde adentro el perfil de la salvadoreñidad: esta es la luz que puede encender la museología en nuestros museos.

\section{Referentes bibliográficos}

Del Castillo Negrete, Manuel, Antología de Textos Básicos, Curso Interamericano de Capacitación Museográfica. Escuela de Conservación, Restauración y Museografía, México, 1993.

Fernández, Luis Alonso, Museología y Museografía, Ediciones del Serbal, Barcelona, 2001. Hernández Hernández, Francisca, Manual de Museología, Editorial Síntesis, Madrid, 1994. Hernández Hernández, Francisca, Planteamientos teóricos de la Museología, editorial Trea, S.L. Barcelona, España, 2006.

Scheiner, Tereza Cristina, "Museología e interpretación de la realidad: el discurso de la historia (documento provocativo)", Icom, marzo de 2006.

Riviere, George Henri, La Museología, editorial Akal, 1993. 


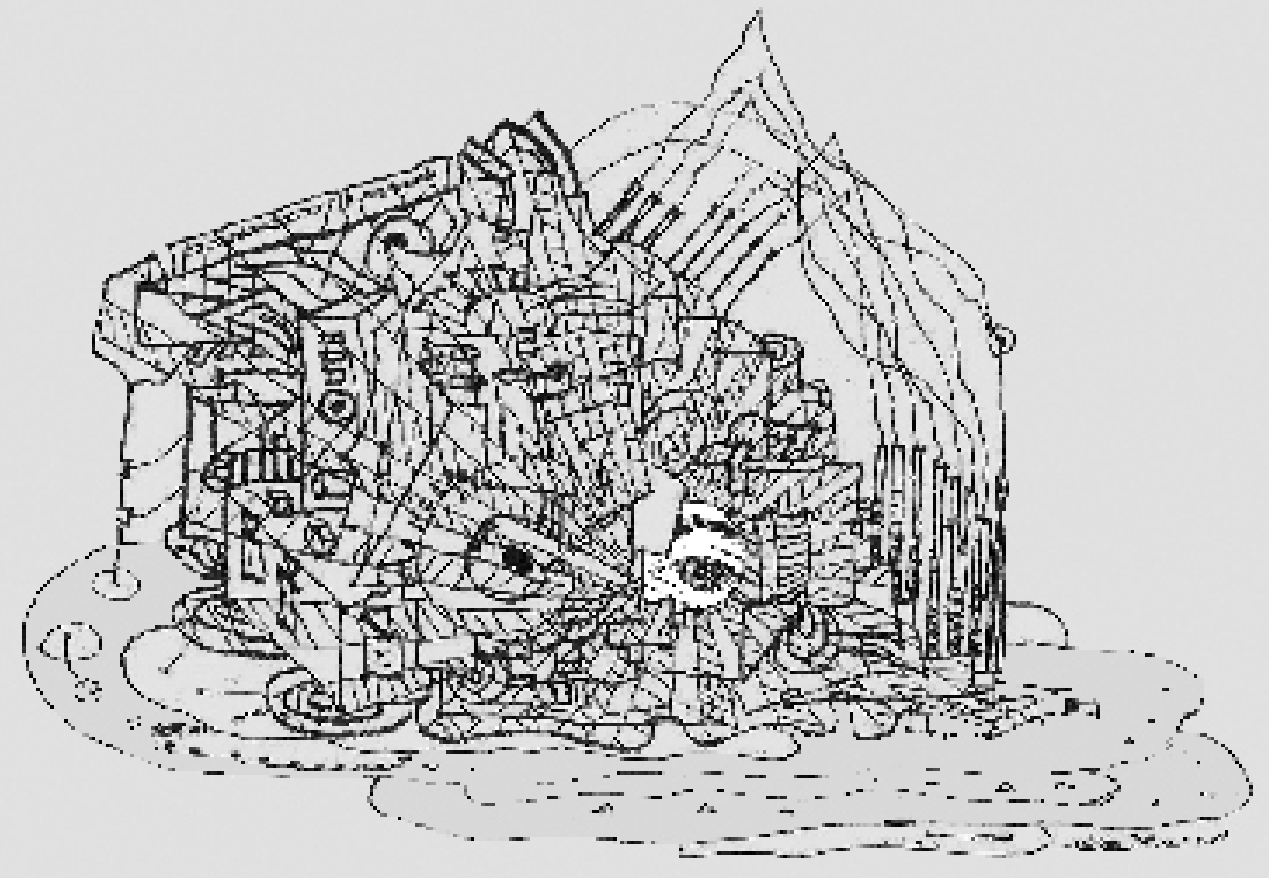

